\title{
O IMPACTO DA TECNOLOGIA NAS RELAÇÕES DE TRABALHO: UMA ANÁLISE À LUZ DA TEORIA DA EFICÁCIA HORIZONTAL DOS DIREITOS FUNDAMENTAIS INESPECÍFICOS DOS TRABALHADORES
}

\author{
Emanueli Dacheri ${ }^{1}$ \\ Rodrigo Goldschmidt ${ }^{2}$
}

Resumo: O presente artigo científico tem por objetivo relacionar a tecnologia e o trabalho e os seus efeitos nas relações laborais, essencialmente quando da mitigação dos direitos da personalidade do trabalhador frente ao uso excessivo do poder de comando do empregador por meio dos aparatos tecnológicos. Para tanto, abordar-se-á a teoria da eficácia horizontal dos direitos fundamentais, como forma de proteção dos direitos violados, garantia de um ambiente laboral sadio e de um trabalho digno.

Palavras-chave: Tecnologia; Trabalho; Direitos Fundamentais; Dignidade da Pessoa Humana.

\section{THE IMPACT OF TECHNOLOGY IN WORK RELATIONS: AN ANALYSIS IN THE LIGHT OF THE THEORY OF THE HORIZONTAL EFFECTIVENESS OF NON- SPECIFIC FUNDAMENTAL RIGHTS OF WORKERS}

\begin{abstract}
This article aims to relate technology and work and its effects on labor relations, especially when mitigating the rights of the personality of the worker against the excessive use of the power of command of the employer through technological devices. To this end, the theory of the horizontal effectiveness of fundamental rights, as a form of protection of violated rights, guarantee a healthy working environment and a decent work will be addressed.
\end{abstract}

Keywords: Technology. Job. Fundamental Rights. Dignity of Human Person.

\section{INTRODUÇÃO}

A tecnologia vem sendo incorporada no mercado de trabalho e nas relações laborais de forma crescente, com o objetivo não somente de facilitar o trabalho humano, mas também, de fomentar a produção e, ainda, de controlar e fiscalizar os trabalhadores.

\footnotetext{
* 1 Mestranda em Direito pela UNESC. Pesquisadora do Núcleo de Pesquisa em Direitos Humanos, Direitos Fundamentais Trabalhistas e Políticas Públicas - PPGD/UNESC. Advogada - OAB/SC 47.930. emanueli.dacheri@gmail.com

* 2 Pós-Doutor em Direito pela PUC/RS. Doutor em Direito pela UFSC. Professor e Pesquisador do PPGD/UNESC. Juiz do Trabalho Titular do TRT12.
}

Rev. de Direitos Fundamentais nas Relações do Trabalho, Sociais e Empresariais | e-ISSN: 2525-9903 | Maranhão | v. 3 | n. 2 | 
Ocorre que, muitas vezes, a busca pela proteção do direito fundamental à propriedade, configurada no poder diretivo do empregador, faz com que este mesmo monitoramento aconteça de forma excessiva, uma vez que a própria legislação não lhe impõe limites específicos, e a consequência é a violação dos direitos da personalidade do trabalhador (intimidade, vida privada, por exemplo), ao ponto de ferir o núcleo essencial dos direitos fundamentais - a dignidade da pessoa humana.

Frente a esta colisão aparente dos direitos fundamentais e o conflito existencial no âmbito das relações privadas, a presente pesquisa propõe-se a analisar a aplicação da teoria da eficácia horizontal dos direitos fundamentais, a fim de resguardar os direitos inespecíficos do sujeito vulnerável na relação trabalhista, no caso, o trabalhador.

Para tanto, utilizou-se do método indutivo e a pesquisa bibliográfica.

No primeiro momento será abordado a tecnologia e seus efeitos nas relações de trabalho. Em seguida, será realizado um estudo sobre os direitos fundamentais e os possíveis conflitos originados nestas relações laborais.

Por último, será feita uma abordagem sobre a teoria da eficácia horizontal dos direitos fundamentais no escopo de se demonstrar a possibilidade de proteção dos direitos e da dignidade da pessoa humana trabalhadora nas relações que envolvem sujeitos privados.

\section{A INTERSECÇÃO TRABALHO-TECNOLOGIA}

$\mathrm{O}$ avanço da tecnologia tem modificado radicalmente a sociedade nos seus mais diversos segmentos; sociais, culturais, políticos, entre outros. Na esfera do trabalho, forma diversa não ocorre, vez que as empresas, desde as de menor porte, assim como as mais vultuosas, incorporam o uso da tecnologia de forma a facilitar a produção em massa dos seus produtos e com isso aumentar seu capital financeiro.

A relação entre trabalho e tecnologia é antiga e presente desde as origens da história da humanidade. Assim ocorreu com a evolução das ferramentas utilizadas na agricultura, com os teares, com o computador, ou seja, a ideia da utilização da tecnologia sempre foi o de facilitar o trabalho humano e como consequência, economizar tempo e esforço (FINCATO; GUIMARÃES; MATTE, 2014).

Todo este processo é devido ao fenômeno da globalização que, em suma, é caracterizado por uma complexa variedade de processos, movidos por uma mistura de 


\section{O IMPACTO DA TECNOLOGIA NAS RELAÇÕES DE TRABALHO: UMA ANÁLISE À LUZ DA TEORIA DA EFICÁCIA HORIZONTAL DOS DIREITOS FUNDAMENTAIS INESPECÍFICOS DOS TRABALHADORES}

influências políticas e econômicas que se potencializa cada vez mais pelas avançadas e complexas tecnologias ao tempo em que transforma as instituições da sociedade em que vivemos (GIDDENS, 2000, p. 43).

Embora este movimento tenha pontos positivos, a verdade é que os direitos dos trabalhadores vêm sendo flexibilizados e as diferenças econômicas e sociais vem sendo potencializadas, havendo respectivamente uma redução nas atividades de garantia e promoção de direitos por meio de políticas públicas:

\footnotetext{
$\mathrm{O}$ aspecto social, à sua vez, também recebeu mudanças; e para pior. A inovação financeira acabou por perpetuar uma síndrome de exclusão social violenta. A mídia de massa, operadora da manutenção do estado reinante, transmite à população a teoria da inexorabilidade do discurso globalizante, incluindo a crença de que esta teoria é necessária e irreversível. É o discurso da manipulação social. Além disso, a ausência do Estado - enfraquecido - na promoção de políticas públicas essenciais faz com que as pessoas de classes sociais baixas vivam marginalizadas em subúrbios que não têm o mínimo de habitabilidade (GODSCHMIDT, 2009, p. 120).
}

As relações de trabalho ganham contornos transnacionais e se afastam de forma constante do modelo trazido pela Revolução Industrial, quando questões sensíveis dos direitos fundamentais ganharam maior proteção, dentre a regulamentação da jornada de trabalho, a observância de padrões mínimos de higiene e saúde no meio ambiente laboral, entre outros direitos angariados (FINCATO, 2011).

Se antes, com a Revolução Industrial, se transferiu a força humana para as máquinas, com o objetivo de aprimorar e facilitar o aumento da produção, atualmente, a transferência das experiências e das capacitações humanas são realizadas aos softwares, por meio de programas desenvolvidos, os quais acabam por substituir a atividade humana. É por esta razão, que hoje vivenciamos uma nova revolução, a informacional (LASTRES; FERRAZ, 1999).

A revolução informacional pode ser entendida como um novo modelo de desenvolvimento que privilegia o uso da tecnologia. Este sistema sucede o industrialismo que ocorreu meados do século XVIII, cuja principal característica consistia na mecanização do trabalho braçal, além da obtenção e descentralização de energia ao longo do processo de produção. O informacionalismo, por sua vez, está voltado para o crescimento da economia, por meio da acumulação de conhecimento aliado ao processo de informação. (FINCATO; GUIMARÃES; MATTE, 2014). 
A rapidez com que se processam as relações informacionais representa lucro, pois, quanto mais célere a produtividade, maior será o capital gerado. Tal exigência faz com que, na maioria das vezes, a produção ocorra de forma contínua e sem pausas, e que o trabalhador exerça sua atividade a qualquer hora, a fim de se conquistar a meta que lhe é proposta.

Essas transformações pelas quais a sociedade vem passando reflete a expansão do capital financeiro, e consequentemente a velocidade com que surgem e se espalham as novas tecnologias, especialmente na informática e na robótica, ganhando cada vez mais espaço no meio social, atingindo as mais variadas classes, algumas preparadas, outras não, e cada vez mais, exigindo do mercado profissionais especializados (MARQUES; STOLZ, 2017).

Segundo Fincato (2011, p. 97), a cognição é a peça que envolve todo este processo:

O conhecimento passa a ser um elemento essencial nessa era global. Encontra-se então, um indivíduo que deve exercer suas funções mais intelectuais na automação. A ele não cabe, como antes, vigiar determinada máquina. Há necessidade de que ele possa controlá-la, prevenir defeitos, além de otimizar (sempre) o seu funcionamento.

Para Toffler (1995, p. 33), “O mais importante fato econômico de nossa era tem sido a ascensão de um novo sistema para a criação de riqueza, baseado não mais nos músculos, mas na mente."

A medida que o processo de globalização invade o meio laboral de forma crescente, aliado ao uso da tecnologia, exige do trabalhador o conhecimento necessário para permanecer em um mercado onde as formas físicas já não são tão essenciais como antes, vez que os bens e os serviços podem atualmente serem comprados, distribuídos e consumidos, por meio do comércio eletrônico, por exemplo (FINCATO, 2011).

A evolução tecnológica traz consigo a necessidade e a implementação de novos processos de produção e a prudência de que o trabalhador se especialize, se capacite, afinal, o trabalho com uso da força humana diminui à medida que se reorganiza por meio do trabalho intelectual e manual.

Com as conquistas advindas da tecnologia nas relações de trabalho, não há mais limites entre os lugares e o tempo, conforme se observa:

A modernidade capitalista apresenta-se como espécie de passagem de um estado de solidez (rigidez) societária (pré-moderna), que historicamente entrou em ebulição, para um outro estado de sociabilidade, onde a evaporação (fluidez) das coisas se torna o conteúdo último das formas; um estado de fluidez total que evolui initerruptamente

Rev. de Direitos Fundamentais nas Relações do Trabalho, Sociais e Empresariais | e-ISSN: 2525-9903 | Maranhão | v. 3 | n. 2 | 


\section{O IMPACTO DA TECNOLOGIA NAS RELAÇÕES DE TRABALHO: UMA ANÁLISE À LUZ DA TEORIA DA EFICÁCIA HORIZONTAL DOS DIREITOS FUNDAMENTAIS INESPECÍFICOS DOS TRABALHADORES}

para ordens materiais e simbólicas cada vez mais complexas e que, impulsionado pelas conquistas tecnológicas liberta os costumes do lugar, as imagens do tempo, a cidadania da nacionalidade (MELLO, 1998, p. 25).

O uso desenfreado de meios tecnológicos permitiu ao homem trabalhar de forma mais célere. Permitiu-lhe, ainda, trabalhar mesmo que fora do seu local de trabalho. O tempo e o espaço de trabalho foram modificados e a distância passou a não ser mais o problema para a concretude das metas, pois desde que se tenha uma internet ágil, o empreendimento conseguirá atravessar horizontes, adentrar em novos mercados, e assim o processo globalizatório vai ganhando corpo.

Contudo, a quebra do tempo-espaço de trabalho trouxe à tona conflitos que desafiam a estrutura do Direito do Trabalho enquanto norma de proteção dos direitos fundamentais, e as tecnologias acabam por tumultuar ainda mais este quadro:

No referido cenário, há diminuição dos postos de trabalho. A automação, a robótica, a tecnologia e a microeletrônica sedimentam-se.

O desemprego passa a apresentar cariz estrutural. $\mathrm{O}$ trabalho fica submetido a um ataque de perda de sua centralidade, consoante o qual deixaria de ser o eixo da sociedade. A externalização gerada pela utilização indiscriminada da terceirização, até mesmo na Administração Pública, solidifica-se. A fragmentação da empresa mostra suas nuanças, com a política de redução de custos.

Avoluma-se o número de mulheres integradas no mercado de trabalho, embora em atividades preponderantemente precarizadas, com tendência de divisão sexual do trabalho no cenário de produção.

A transferência antes ocorrida da mão de obra do setor primário (agrícola) para o secundário (de manufatura, industrial), após para o de serviços (terciário), ocorre hoje para o setor quaternário (de conhecimento, sociedade informacional) (OLIVEIRA, 2010, p. 34).

E Delgado (2008, p. 564-565) segue:

[...] houve uma redução de proletariado industrial tradicional ("mestres em manufatura, carpinteiros, torneiros mecânicos, chefes administrativos") que cedeu lugar a formas mais flexíveis de contratação trabalhista presentes nas mais diversas modalidades de trabalho precarizado-toyotizado, com destaque para os "trabalhadores de telemarketing e call center, motoboys, empregados de fast-food, de hipermercados" entre outros. Paradoxalmente, houve um aumento no proletariado de serviços básicos ("asseio e conservação, segurança pública e privada, construção civill", entre outros), sobretudo devido à ênfase nos processos de terceirização. Além disso, em meio ás flexíveis formas de contratação trabalhista também se destaca a maciça utilização de mão de obra informal ou "subterrânea" o que, em geral, implica na maior precariedade de trabalho [...] Outra tendência presente no atual mercado de trabalho é o crescimento do desemprego entre trabalhadores com maior tempo de escolaridade, sobretudo

Rev. de Direitos Fundamentais nas Relações do Trabalho, Sociais e Empresariais | e-ISSN: 2525-9903 | Maranhão | v. 3 | n. 2 | 
jovens e adultos com idade máxima de quarenta anos. Paradoxalmente, quando os trabalhadores qualificados ocupam postos de trabalho, o fazem em ocupações de menor grau de exigência profissional, a marginalização dos trabalhadores com baixa qualificação" (...) Além disso, o mercado conta com o desenvolvimento do trabalho no "terceiro setor", onde formas alternativas e comunitárias de trabalho se destacam. É nesse contexto que se apresenta o trabalho voluntário como alternativa ao desemprego, mas muitas vezes o que se percebe é que ele é utilizado à margem do Direito do Trabalho, enquanto mecanismo de descaracterização de relação de emprego.

O uso da tecnologia, desde os tempos mais remotos, quando aliado ao trabalho, foi feito para facilitar o labor do homem, que teria mais tempo destinado à sociabilidade, ao convívio familiar, à capacitação e à educação. No entanto, as promessas que agregaram a tecnologia ao trabalho, de certo modo, não se concretizaram, pois, o trabalho aumentou e o tempo livre foi reduzido. As interações sociais também aumentaram com o uso da tecnologia, essencialmente, da internet, contudo, de forma isolada, eis que tudo ocorre através de uma tela de computador, tablet, celular, etc. O contato físico também deixou de ser essencial para a existência das relações.

Trabalha-se excessivamente devido a confusão que se criou em razão da identificação do real ambiente de trabalho, além da ausência de linhas limítrofes visíveis e definidas entre a figura do trabalhador e a do ser humano enquanto ser social (FINCATO; GUIMARÃES; MATTE, 2014).

O trabalhador foi levado à hiperconcexão, modalidade neo-escravista, que podem acarretar danos existenciais, como o adoecimento psíquico:

O velho modelo econômico de produção e prestação laboral, baseado na indústria, já vem há tempos dando mostras de sua obsolescência frente a esta nova dinâmica social, alicerçada no atroz processamento e permuta de informações. As barreiras geográficas estão sendo "reduzidas" cada vez mais, trazendo consigo a aproximação de novos mercados e novas demandas. A quantidade de informação tornou-se uma medida sem escala: quanto mais, melhor. Essas mudanças introduzem alterações significativas nas relações humanas e nas estruturas de subordinação das relações laborais. Fazem desprender, cada vez mais, daquele modelo de outrora, denominado trabalho "alienado clássico". As alterações inserem, nessa estrutura laboral, de pressão da categoria patronal sobre a econômica, uma nova dinâmica, que rompe com as distâncias geográficas, revelando uma subordinação contínua e uma disponibilidade diuturna de seus sujeitos; cria uma espécie de escravidão, a psicológica.

O ser humano, hoje, se vê escravo de uma constante necessidade de utilização de internet, a rede mundial de compartilhamento e transferência de dados (FINCATO; GUIMARÃES; MATTE, 2014, p. 21). 


\title{
O IMPACTO DA TECNOLOGIA NAS RELAÇÕES DE TRABALHO: UMA ANÁLISE À LUZ DA TEORIA DA EFICÁCIA HORIZONTAL DOS DIREITOS FUNDAMENTAIS INESPECÍFICOS DOS TRABALHADORES
}

Juntamente com toda a evolução desencadeada com a intersecção trabalho-tecnologia, importantes questionamentos circundam a matéria que baliza as relações sociais e laborais, atuais e principalmente as futuras, ao ponto de se indagar se todo este avanço estaria fazendo bem para a saúde psicológica do ser humano trabalhador, enquanto detentor de direitos sociais e laborais, bem como se isso vem respeitando a dignidade humana ou se, novamente, há mitigação dos direitos fundamentais trabalhistas.

O capitalismo acelerado e a instantaneidade com que circundam hoje as relações sociais e laborais, faz com que o mercado de trabalho seja construído na lógica semelhante a dos computadores ligados em rede, máquinas de excelência, processadores de dados cada vez mais velozes. Porém, o homem é um ser limitado às circunstâncias que abrangem determinado momento, bem como as suas qualidades e consequentemente a sua velocidade para a realização das tarefas poderá ser boa ou ruim, sendo impossível desejar que o trabalho seja realizado à velocidade da luz, em razão do uso da tecnologia (FINCATO; GUIMARÃES; MATTE, 2014).

A lógica da velocidade mecanicista impregna hoje as relações sociais e laborais:

\begin{abstract}
O que se quer dizer aqui é que essa nova velocidade, que surgiu da introjeção do exímio e célere processamento de dados, possibilitado pelas novas ferramentas de tecnologia e comunicação, trouxe consigo a criação de novos paradigmas de funcionalidade, desempenho e relações humanas. Isso altera consubstancialmente as relações interpessoais e tanto pessoais do ser humano para/com ele mesmo. A ideia de processamento de dados, velocidade e eficiência que se tem das máquinas não deve e não poderia servir de paradigma para as ações humanas. O que ocorre atualmente, todavia, é uma exigência absurda por parte das pessoas - dos empregadores principalmente - para que se redirecionem as ferramentas tecnológicas de uma forma que potencialize a própria capacidade de processamento de dados do seu usuário, uma gestão de informação sobre-humana (FINCATO; GUIMARÃES; MATTE, 2014, p. $30)$.
\end{abstract}

O processo globalizatório gerado pelo avanço das tecnologias nas relações de trabalho não podem retroceder o amadurecimento social do ser humano e a dignidade humana do trabalhador. Os direitos fundamentais trabalhistas devem ser preservados dentro deste novo contexto histórico, a fim de que se evitem medidas e interpretações que os relativizem em âmbito universal (FINCATO, 2011).

Deste modo, cabe aos operadores do direito a cautela de resguardo e proteção dos direitos fundamentais da classe trabalhadora, em especial, os de personalidade, que serão 
abordados nos tópicos seguintes, mesmo sobre esta gigante mutação tecnológica, capaz de gerar os mais variados e imponderáveis efeitos.

\title{
3 DIREITOS FUNDAMENTAIS E O USO DA TECNOLOGIA NAS RELAÇÕES DE TRABALHO
}

A ascensão tecnológica nas relações de trabalho ofertou ao homem diversos benefícios, muito embora tenha também trazido uma série de riscos aos direitos do empregado. A utilização desse meio, além de alterar os instrumentos de produção e de distribuição do tempo, transformou o local de trabalho num ambiente de controle e monitoramento com o fim de, pretensamente, preservar o patrimônio do empregador.

Esta evolução acabou distanciando a figura do empregado e do empregador, gerando por consequência a diminuição do nível de confiança e presunção de boa-fé que deveria estar presente na relação laboral e alterou, de forma visível a relação de emprego, originando conflitos decorrentes da violação dos direitos da personalidade do empregado em razão do exercício do poder diretivo do empregador pelo uso excessivo da tecnologia no meio ambiente laboral.

O meio ambiente laboral é regulamentado por $\mathrm{Lei}^{3}$ e assim pode ser definido:

\begin{abstract}
A lei $n^{\circ}$ 6.938, de 31 de agosto de 1981 (Política Nacional do Meio Ambiente), em seu art. $3^{\circ}, \mathrm{I}$, atreve-se a elaborar o difícil conceito de meio ambiente. $\mathrm{O}$ ambiente de trabalho, por sua vez, apresenta-se "como o local em que são realizadas as atividades nucleares da empresa e desenvolvidos os processos produtivos pelos empregados" [...] No meio ambiente de trabalho, o empregador lança mão da utilização de diversos meios eletrônicos para aperfeiçoar a produção da empresa, mas também para exercitar seu poder de comando, fiscalizando o trabalhador através de mecanismos tecnológicos enquanto este cede sua mão de obra (FINCATO; GUIMARÃES; MATTE, 2014, P. 104).
\end{abstract}

Os meios eletrônicos comumente utilizados nas relações de trabalho, passíveis de causarem prejuízos aos direitos à intimidade e à privacidade do empregado, segundo Barros (2012), podem ser analógicos ou digitais; polígrafos, detectores de metais, telefones fixos e celulares, câmeras de vídeo e o computador, por meio de duas ferramentas essenciais, a internet e o correio eletrônico, sem a exclusão de outros vários equipamentos.

$3 \quad$ Lei $n^{\circ} 6.938$, de 31 de agosto de 1981 .

Rev. de Direitos Fundamentais nas Relações do Trabalho, Sociais e Empresariais | e-ISSN: 2525-9903 | Maranhão | v. 3 | n. 2 |

p. $66-87$ | Jul/Dez. 2017. 
O empregador utiliza todo este aparato tecnológico para aperfeiçoar a produção da empresa e também para consolidar seu poder de comando, fiscalizando o trabalhador enquanto labora por meio dos mais diversos mecanismos tecnológicos. Ocorre que, no exercício das suas prerrogativas patronais, o empregador muitas vezes excede seus poderes de comando e de trato para com o empregado e acaba ferindo vários direitos da sua personalidade, tais como a honra, imagem, privacidade e intimidade (FINCATO; GUIMARÃES; MATTE, 2014).

O empregador é detentor de todo complexo organizacional de produção, inclusive sobre os serviços prestados pelo trabalhador. O seu poder diretivo está previsto no art. $2^{\circ}$ da $\mathrm{CLT}^{4}$, bem como definido como um direito fundamental expresso na Constituição da República $^{5}$, razão pela qual é seu direito monitorar a prestação de serviço do empregado.

O poder diretivo também pode ser visto como sinônimo de poder de comando e assim pode ser conceituado:

Poder diretivo do empresário é a capacidade, oriunda do seu direito subjetivo, ou então da organização empresarial, para determinar a estrutura técnica e econômica da empresa e dar conteúdo concreto à atividade do trabalhador, visando a realização das finalidades daquela (MAGANO, 1982, p. 1).

As formas de expressão do poder diretivo do empregador são múltiplas, mas podem sintetizar-se no ato de regulamentar a relação de emprego, distribuir, dirigir, orientar, fiscalizar, adequar a prestação às necessidades da empresa e impor sanções disciplinares ao empregado faltoso (CAMINO, 2004).

A legislação brasileira é omissa quanto aos limites ao poder diretivo do empregador, no entanto, a doutrina elenca alguns, tais como, o princípio da dignidade da pessoa humana, os próprios direitos da personalidade, a Constituição, as leis, os contratos e as normas coletivas. São limites também a boa fé e a função social da propriedade, significando que, embora seja o empregador proprietário da empresa e de todos os bens nela existentes, ele não pode extrapolar sua gerência de maneira a violar os direitos dos trabalhadores, em especial os da personalidade (FINCATO; GUIMARÃES; MATTE, 2014).

\footnotetext{
4 Considera-se empregador a empresa, individual ou coletiva, que, assumindo os riscos da atividade econômica, admite, assalaria e dirige a prestação pessoal de serviço. $5 \quad \mathrm{CF}$, art. $5^{\circ}$, XXII.
}

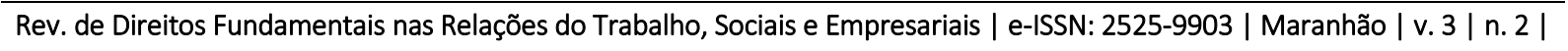
p. 66 - 87 | Jul/Dez. 2017. 
Mesmo diante da ausência de lei que regulamente a fiscalização e o controle do empreendimento, o certo é que o "respeito aos direitos fundamentais do trabalhador, como sua dignidade, intimidade ou vida privada, não podem ser ignorados pelo empregador no uso de seu poder diretivo", conforme afirma Mantovani Junior (2010).

Sobre os direitos e garantias fundamentais ${ }^{6}$, a Constituição da República os trouxe em seu Título II, subdividindo-os da seguinte forma: direitos e garantias individuais e coletivos; direitos sociais; direitos de nacionalidade; direitos políticos e direitos relacionados à existência, organização e participação em partidos políticos.

Cumpre ressaltar, a propósito, que os direitos e garantias fundamentais não se esgotam no mencionado título do texto constitucional. Em verdade, apresentam-se disseminados por toda a Constituição, encontrando espaço ainda em tratados e convenções internacionais ${ }^{7}$.

Costuma-se classificar os direitos humanos ou fundamentais em diferentes gerações ou dimensões, conforme seu desenvolvimento histórico (conquista), bem como diante do objeto de sua tutela. Dessa forma, são direitos de primeira dimensão aqueles que visam a estabelecer limites ao poder público, cumprindo a função de direitos de defesa dos cidadãos frente ao Estado. São também nominados de liberdades públicas, já que visam a impedir a indevida ingerência estatal na vida do indivíduo (VECCHI, 2016).

Ao lado situam-se os diretos de segunda dimensão, os direitos sociais, econômicos e culturais. Visam a obrigar o poder público a agir positivamente na construção de uma sociedade com oportunidades de desenvolvimento e crescimento de todos, propiciando a igualdade de seus integrantes. Neles, o dever do Estado vai além do mero não agir, exige-se-lhe prestação, inclusive com desembolso de disponibilidades econômicas (VECCHI, 2016).

Por fim, apresentam-se os direitos de terceira dimensão, associados à busca e criação de uma sociedade, tanto quanto possível, fraterna, tendo-se em vista a proteção de bens que afetam e interessam à coletividade social (VECCHI, 2016).

Ressalta-se que tais direitos foram galgados paulatinamente, sendo que inicialmente apenas os primeiros eram reconhecidos, e que os últimos somente vieram a ser conquistados

\footnotetext{
6 Destaca-se que o conceito de direitos e garantias fundamentais distingue-se do conceito de garantias institucionais que são aqueles direitos conferidos a determinadas instituições. Assim, a maternidade, a família, a liberdade de imprensa, entre outros, são instituições protegidas diretamente como realidades sociais objetivas e só, indiretamente, se expandem para a proteção dos direitos individuais. (MORAES, 2003, p. 62).

$7 \quad$ Sobre o tema, dispõe o $\$ 2^{\circ}$ do art. $5^{\circ}$ da CRFB. Os direitos e garantias expressos nesta Constituição não excluem outros decorrentes do regime e dos princípios por ela adotados, ou dos tratados internacionais em que a República Federativa do Brasil seja parte.
}

Rev. de Direitos Fundamentais nas Relações do Trabalho, Sociais e Empresariais | e-ISSN: 2525-9903 | Maranhão | v. 3 | n. 2 | 


\title{
O IMPACTO DA TECNOLOGIA NAS RELAÇÕES DE TRABALHO: UMA ANÁLISE À LUZ DA TEORIA DA EFICÁCIA HORIZONTAL DOS DIREITOS FUNDAMENTAIS INESPECÍFICOS DOS TRABALHADORES
}

após muito tempo. É necessário reconhecer que todos convivem harmoniosamente sem tornar desatualizada, e nem mesmo desnecessária, a etapa anterior. Esta é, inclusive, a razão pela qual a doutrina tem preferido a denominação de dimensões de direitos, ao invés de gerações.

Neste contexto, para melhor elucidar as três dimensões dos direitos fundamentais, colhese a contribuição de Bonavides (2000, p. 517-523):

\begin{abstract}
Os direitos de primeira geração são os direitos da liberdade, os primeiros a constarem do instrumento normativo constitucional, a saber, os direitos civis e políticos [...] têm por titular o indivíduo, são oponíveis ao Estado, traduzem-se como faculdades ou atributos da pessoa e ostentam uma subjetividade que é seu traço mais característico; enfim, são direitos de resistência ou de oposição perante o Estado. [...] Os direitos de segunda geração merecem um exame mais amplo. [...] São os direitos sociais, culturais e econômicos bem como os direitos coletivos ou de coletividades [...] Os direitos de terceira geração tendem a cristalizar-se neste fim de século enquanto direitos que não se destinam especificamente à proteção dos interesses de um indivíduo, de um grupo ou de um determinado Estado. Têm primeiro por destinatário o gênero humano mesmo, num momento expressivo de sua afirmação como valor supremo em termos de existencialidade concreta. [...] Emergiram eles da reflexão sobre temas referentes ao desenvolvimento, à paz, ao meio-ambiente, à comunicação e ao patrimônio comum da humanidade.
\end{abstract}

Os direitos fundamentais ou direitos humanos ${ }^{8}$ como também são denominados, diante de sua importância central na ordem constitucional, são dotados de rigidez, de tal modo que o legislador infraconstitucional não possa com facilidade, alterá-los ou suprimi-los. Destaca-se que, dentre os limites materiais ao poder de emenda do texto original, veda-se a abolição, ao menos, dos direitos e garantias individuais?.

Ainda, com relação a distinção de direitos humanos e direitos fundamentais acrescentase:

Os direitos humanos são tratados como direitos inalienáveis que têm sua origem na própria natureza humana e que aspiram à validade universal, sem estarem adstritos a uma determinada ordem constitucional. Assim, estariam previstos em documentos internacionais e não possuiriam, em regra, meios jurídicos eficazes para sua exigência. Por sua vez, os direitos fundamentais são considerados aqueles direitos humanos que estão consagrados e positivados, que têm previsão mais precisa e restrita, estando em consonância com uma determinada ordem constitucional; existe, assim, em caso de

\footnotetext{
8 Embora tratados como sinônimos, sustenta-se na doutrina que a distinção entre direitos humanos e fundamentais reside na circunstância de que, enquanto os primeiros são os inerentes a todos os seres humanos pela tão só natureza de seu titular, os últimos designam tais direitos positivamente previstos na ordem constitucional de um Estado determinado. (BONAVIDES, 2000, p. 514).
}

$9 \quad$ Art. $60, \S 4^{\circ}$, CRFB.

Rev. de Direitos Fundamentais nas Relações do Trabalho, Sociais e Empresariais | e-ISSN: 2525-9903 | Maranhão | v. 3 | n. 2 | 
violação, a previsão de um recurso judicial para sua exigência e sua concretização prática (VECCHI, 2009, p. 151).

Assim, direitos fundamentais são aqueles que objetivam respeitar a dignidade da pessoa humana, protegendo-a do arbítrio estatal, criando condições necessárias para uma vida em sociedade livre de preconceitos e visando ao desenvolvimento do ser humano (VECCHI, 2016).

Destaca-se, em complemento:

\begin{abstract}
Os direitos fundamentais, normas jurídicas positivas constitucionais que são, devem ser vistos como a categoria instituída com o objetivo de proteção à dignidade, à liberdade e à igualdade humanas em todas as dimensões. O termo fundamental, é certo, deixa clara a imprescindibilidade desses direitos à condição humana $\mathrm{e}$ ao convívio social (CAMARGO, 2009, p. 13).
\end{abstract}

Dessa forma, dada a importância que assumem os direitos fundamentais na ordem jurídica e considerada a sua natureza de norma constitucional própria ${ }^{10}$, pode-se concebê-los como princípios constitucionais do mais alto quilate. Diga-se, em reforço, que o princípio da dignidade da pessoa humana, mais do que princípio constitucional, constitui a essência e a vértebra principal da Constituição da República.

A ideia de dignidade da pessoa humana, parte do pressuposto de que o homem, em virtude tão-somente de sua condição humana e independente de qualquer circunstância, é titular de direitos que devem ser reconhecidos e respeitados por seus semelhantes e pelo Estado. É incontroverso que o ser humano possui valor próprio e intrínseco, que o identifica como tal, pois, como adverte Barretto (2010, p. 62):

Nesse contexto é que pode situar o princípio da dignidade humana em toda a sua
importância jurídica. Precisamente porque o princípio da dignidade encontra-se como
primeiro princípio, fonte de todos os demais, ele deve permanecer subsidiário, A sua
utilização deverá restringir-se às questões em que nenhum outro princípio ou conceito
jurídico possa ser utilizado, sob pena de ocorrer a dissolução de todo direito na
dignidade. Tudo passa a ser então questão de dignidade e com isto o sistema jurídico
esvazia-se de qualquer sentido normativo. A proliferação do uso indiscriminado do
princípio da dignidade humana na argumentação judicial faz com que se encontre
onipresente, mesmo quando o próprio texto da lei atende às necessidades da ordem
jurídica.

10 Distinguem-se as normas constitucionais próprias ou materiais das normas constitucionais impróprias ou meramente formais, na medida em que aquelas tratam de matéria essencialmente afeta à Constituição, tais como a organização do Estado e do governo, os direitos fundamentais e a divisão de poderes e de competências, enquanto que estas, sem ter relação com conteúdo de tal natureza, apenas encontram-se registradas no texto da constituição por opção do constituinte. (MORAES, 2003, p. 544-546).

Rev. de Direitos Fundamentais nas Relações do Trabalho, Sociais e Empresariais | e-ISSN: 2525-9903 | Maranhão | v. 3 | n. 2 | 
Segundo Souto Maior (2006, p. 92), apesar de, sob a ótica da filosofia moderna, o trabalho dignificar o homem, contraditoriamente, a utilização da tecnologia no ambiente de trabalho retira a dignidade humana, impondo limites ao empregado na medida em que o trabalho interfere e avança sobre a sua intimidade e privacidade.

Assinala-se que a intimidade e a privacidade, advém dos direitos de personalidade, que são prerrogativas particulares de caráter fundamental, os quais funcionam como verdadeiros escudos contra os abusos do Estado e demais particulares (VECCHI, 2016).

A Constituição Federal $^{11}$ arrola como principais direitos de personalidade à intimidade, à vida privada, à honra e à imagem, sem a exclusão de outros disseminados no texto constitucional, assegurando, inclusive, o direito à indenização pelo dano material ou moral decorrente de sua violação. O Código Civil ${ }^{12}$, dispõe sobre a temática dos aludidos direitos de forma expressa. Já a Consolidação das Leis Trabalhistas ${ }^{13}$, não trata de forma específica sobre a proteção dos direitos da personalidade do trabalhador, frente ao poderio empresarial, apenas dispondo sobre a vedação da revista íntima ${ }^{14}$.

$\mathrm{O}$ direito à privacidade ou à vida privada assim pode ser definido:

Este direito corresponde à não-interferência e não-intromissão, seja do Estado ou de qualquer um na esfera da intimidade das pessoas e, com esta configuração, equiparase às liberdades públicas clássicas, ou direitos fundamentais de primeira geração, reclamando com isto medidas similares de proteção e garantia (VERGUEIRO, 2005 apud FINCATO; GUIMARÃES; MATTE et al., 2014, p. 100).

Assim, diante do uso excessivo da tecnologia no ambiente de trabalho, surge de um lado, o direito de propriedade garantido ao empregador e, de outro, a reserva da intimidade e da vida privada, havendo uma colisão entre direitos fundamentais: "Há uma colisão autêntica de direitos fundamentais quando o exercício de um direito fundamental por parte de seu titular colide com exercício do direito fundamental por parte de outro titular, ocorrendo um verdadeiro choque ou conflito de direitos" (CANOTILHO, 2000, p. 1229).

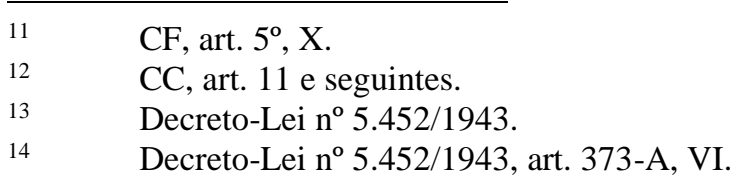


Ainda, sobre o tema, esclarece Hainzenreder Junior (apud, FINCATO; GUIMARÃES; MATTE et al., 2014, p. 93), que há um choque entre princípios, tendo em vista que de um lado da relação de emprego estão os direitos à intimidade, à privacidade, ao sigilo de correspondência do empregado, e de outro, encontra-se o empregador, detentor do poder diretivo, legitimado pelo direito de propriedade sobre todos os bens e serviços que integram a empresa.

É questionável, deste modo, a forma pela qual se deva assegurar o direito à privacidade do empregado em um ambiente de trabalho monitorado por meios eletrônicos, em face ao poder de comando do empregador:

\begin{abstract}
Os direitos à privacidade e à intimidade nas relações de trabalho tendem a ganhar maior atenção com vertiginoso crescimento tecnológico, pois se de um lado temos o direito do empregador de conduzir a produção e a fiscalização do empreendimento; do outro temos os sólidos e fundamentais direitos à privacidade e à intimidade do trabalhador. Em princípio, e como exposto no decorrer do modesto artigo, não há posicionamento normativo específico para o problema que assegure em todas as ocasiões os direitos personalíssimos. O que há, a bem da verdade, são conjugações de regras e princípios - que, indiretamente, protegem timidamente tais direitos. Até que o legislador estabeleça normas que efetivamente tutelem os direitos de personalidade, sobretudo, regras que atendam os anseios sociais da nova era da vigilância eletrônica, os direitos à privacidade e à intimidade nas relações de trabalho estarão sob constante ameaça (FINCATO; GUIMARÃES; MATTE, 2014, p. 110).
\end{abstract}

O fato é que, a privacidade e a intimidade, como direitos fundamentais, merecem especial atenção no ambiente de trabalho, principalmente em razão da intensificação do uso da tecnologia por parte do empregador para o controle e a fiscalização do empregado.

Assim, considerando que a colisão de direitos fundamentais acima apresentada é invocada no âmbito da relação entre particulares, que envolve as figuras de trabalhador e empregador, necessário uma abordagem sobre a teoria horizontal da eficácia dos direitos fundamentais, assunto do tópico seguinte.

\title{
4 A EFICÁCIA DOS DIREITOS FUNDAMENTAIS INESPECÍFICOS NAS RELAÇÕES DE TRABALHO
}

A dignidade da pessoa humana é considerada o núcleo essencial dos direitos fundamentais, conforme já visto anteriormente. Estes direitos fundamentais são os elementos 
basilares na defesa do indivíduo contra as ações do poder público, concretizada pela eficácia vertical das normas fundamentais.

Segundo Siqueira (2016, p. 78), “[...] essa eficácia não é algo fácil de atingir, há muitas variáveis que devem ser consideradas, a exemplo da vontade política dos governantes e a ausência dos órgãos competentes para garantir a sua concretização.” O autor afirma, ainda, que a garantia destes direitos fundamentais tende a evitar que o indivíduo vulnerável sofra com abusos de poder e violência estatal.

Todavia, não é somente do Estado que o indivíduo vulnerável deve ter garantido os seus direitos fundamentais, mas também, com relação aos particulares:

Em sua feição clássica, a teoria da eficácia horizontal dos direitos fundamentais defende que esses direitos não são oponíveis apenas contra o Estado e seus agentes, o que teria sentido quando de seu surgimento histórico, mas também no seio das relações privadas, diretamente (eficácia ou relevância imediata) ou por meio de um ato estatal que intermedeie essa aplicação (eficácia ou relevância mediata) (MELO, 2012, p. 30-31).

Sobre a eficácia dos direitos fundamentais destaca-se que, tanto a doutrina quanto a jurisprudência têm constatado que não raras vezes não é o Estado o "grande vilão" frente aos direitos fundamentais, mas, sim, os sujeitos privados, especialmente os dotados de poder, social ou econômico. Essa constatação ganha importância quando a globalização aumenta, de forma circunstancial, o poder de grandes grupos privados (VECCHI, 2016).

O empregado, inserido na estrutura empresarial, tem a sua atividade subordinada ao empregador que pode praticar atos capazes de violar direitos fundamentais da personalidade, entre outros. Essa vinculação dos particulares aos direitos fundamentais, também é denominada de eficácia horizontal dos direitos fundamentais, podendo ser considerado elemento indispensável na garantia de proteção da dignidade da pessoa humana trabalhadora, frente aos abusos de direito cometidos pelo empregador em razão do seu poder diretivo (SIQUEIRA, 2016).

Os direitos fundamentais devem acompanhar o trabalhador em todos os momentos existes dentro do contexto da relação de trabalho, todavia, infelizmente, na maioria das vezes, não é o que ocorre:

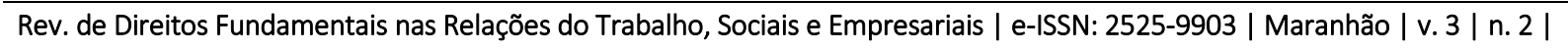
p. 66 - 87 | Jul/Dez. 2017. 


\begin{abstract}
Além disso, existe outro grande problema que tem abalado as relações de trabalho, ou seja: a desconsideração do trabalhador como sujeito integral, como pessoa humana dotada de direitos humanos fundamentais que devem ser entendidos em sua indivisibilidade, direitos de que o trabalhador não abre mão ao se tornar sujeito de uma relação de emprego, direitos que não podem ficar "na porta da fábrica" esperando o término da jornada de trabalho. Esse problema também se torna global, ou seja: é enfrentado por trabalhadores nos mais diversos "cantos da Terra", sendo facilitado pela flexibilização, que enfraquece, cada vez mais a posição dos trabalhadores (VECCHI, 2009, p.55).
\end{abstract}

Em casos assim, onde as partes envolvidas são materialmente desiguais, e direitos fundamentais estiverem sob ameaça ou forem efetivamente violados, a proteção a estes direitos deve estar alicerçada na própria proporção de desigualdade, minimizando a proteção da autonomia da vontade, uma vez que a parte mais vulnerável, no caso o trabalhador, sofrerá consequências maiores pela violação de seus direitos do que pela diminuição da sua autonomia volitiva (SIQUEIRA, 2016).

Várias são as teorias desenvolvidas que se propõe à aplicação dos direitos fundamentais nas relações privadas, dentre elas: teoria da aplicabilidade direta ou eficácia imediata; teoria da aplicabilidade indireta ou eficácia mediata; teoria da não aplicabilidade ou state action (SIQUEIRA, 2016; STENMETZ, 2004; VECCHI, 2016).

Segundo Vecchi (2016), a teoria da não aplicabilidade ou state action é traduzida na impossibilidade da aplicação dos direitos fundamentais nas relações essencialmente privadas, cabendo a aplicação desses direitos, tão somente, nas relações em que os particulares exercem alguma função estatal, ou então, quando se possa imputar ao Estado a conduta de um particular que viole um direito fundamental. Referida teoria é utilizada predominantemente nos Estados Unidos da América e tem sua base na visão liberal.

A teoria da aplicabilidade indireta ou eficácia mediata dos direitos fundamentais na esfera privada é adotada na Alemanha. É uma construção intermediária entre a teoria da não aplicabilidade e aquela que sustenta a incidência direta destes direitos na esfera privada, e consiste na aplicação indireta dos direitos fundamentais na esfera privada, por meio da intermediação de um órgão estatal. Para referida teoria é necessário que se preserve a autonomia de vontade (SARMENTO, 2010).

Por sua vez, a teoria da aplicabilidade direta ou eficácia imediata é a mais aceita pela doutrina pátria e pelo Supremo Tribunal Federal, que vem entendendo ser a mais adequada ao ordenamento vigente. Também teve a sua origem na Alemanha, sendo o seu objetivo a defesa da existência de uma vinculação direta dos direitos fundamentais, tanto nas relações sociais 
existentes entre o indivíduo e o Estado, assim como também nos conflitos oriundos entre sujeitos particulares (SIQUEIRA, 2016).

Para esta teoria há a possibilidade de os indivíduos buscar a defesa dos seus direitos fundamentais frente aos particulares, neste sentido:

Postula-se por uma eficácia não condicionada à mediação concretizadora dos poderes públicos, isto é, o conteúdo, a forma e o encalce da eficácia jurídica não dependem de regulações legislativas específicas e nem de interpretação e de aplicações judiciais, conforme aos direitos fundamentais, de textos de normas imperativas de direito privado, de modo especial, daqueles portadores de cláusulas gerais (STEINMETZ, 2004, p. 167).

É importante, no entanto, que a aplicação da teoria da eficácia direta ou imediata ao caso concreto seja realizada utilizando-se dos critérios da ponderação, a fim de que a autonomia da vontade não seja suprimida, ou seja, faz-se necessário o sopesamento entre os direitos em conflito, “[...] quanto maior for a limitação a um direito, maior deverá ser a importância da concretização do outro direito em oposição àquele limitado" (SIQUEIRA, 2016, p. 83).

No mesmo sentido, Vecchi (2011, p. 122) acrescenta:

Com efeito, quando da eficácia dos direitos fundamentais nas relações de emprego,
não raro ter-se-á que enfrentar problemas de colisão entre os direitos fundamentais do
empregado e interesses patronais que também são protegidos pelo ordenamento
jurídico. Apesar disso, não se pode perder de vista que muitas vezes, quando se debate
a questão da liberdade, são confundidas as liberdades pessoais e as chamadas
"liberdade econômicas" (liberdade contratual e de empresa), colocando-as no mesmo
patamar, o que é um erro.

Apresentadas as teorias que sustentam a eficácia horizontal dos direitos fundamentais, cumpre ressaltar que o principal objetivo a ser conquistado com a sua aplicação no âmbito das relações de trabalho é sempre a garantia do exercício dos direitos fundamentais em sua plena potencialidade, fundamentado na dignidade da pessoa humana (SARMENTO, 2010).

O mesmo ocorre no contexto do uso da tecnologia nas relações de trabalho. Os grandes avanços nos meios da comunicação, vigilância e controle da execução do trabalho, fazem com que a figura do trabalhador, cada vez mais fragilizado em sua condição de operário e ser humano, careça de maior atenção à garantia e proteção dos seus direitos, essencialmente os de personalidade, no âmbito das relações laborais (SIQUEIRA, 2016). 
Nota-se que o empregado não perde a sua condição de pessoa humana, de cidadão, ao ingressar numa relação de emprego, na qual necessita que os vários aspectos da sua personalidade e dignidade sejam protegidos, não bastando apenas a proteção dos seus direitos puramente sociais, também denominados de direitos específicos ${ }^{15}$, mas também importa que seja tratado com dignidade e respeito (VECCHI, 2009).

É por esta razão que os direitos fundamentais laborais inespecíficos ganham maior importância dentro deste contexto, ou seja, faz-se necessário que se garanta muito mais que os direitos trabalhistas ao empregado, é preciso que se tutele sua condição de ser humano, no escopo de garantir a sua dignidade como pessoa (SIQUEIRA, 2016).

Para Vecchi (2016), os direitos fundamentais inespecíficos são todos aqueles que o trabalhador possui, não enquanto sujeito na relação de trabalho, mas sim enquanto pessoa humana, como um cidadão que faz parte de determinada sociedade e podem ser definidos como os direitos à liberdade de expressão, à intimidade, à imagem, ao devido processo legal, por exemplo, não podendo o trabalhador ser despido destes direitos mesmo enquanto figura na posição vulnerável de empregado.

Os direitos laborais inespecíficos, para arrematar:

[...] são aqueles que decorrem da condição humana do trabalhador. São direitos do trabalhador cidadão e precisam ser exercitados como direitos de personalidade impregnados na relação de trabalho. Pode-se citar como exemplos: o direito à intimidade e vida privada, direito de liberdade de expressão, direito à proteção, à honra, direito à liberdade ideológica e religiosa, direito à proteção contra a discriminação, etc. Embora não sejam direitos especificamente ligados ou decorrentes do contrato de trabalho, são inerentes ao ser humano e, por isso, devem ser garantidos na duração da prestação de serviços.

$\mathrm{Na}$ verdade, pode-se afirmar que ocorre um acréscimo ao contrato celebrado, de todos os direitos e deveres inerentes à manutenção da dignidade da pessoa humana, que condicionam o exercício da contratualidade entre as partes. Isso porque o trabalhador não pode renunciar àqueles direitos $\mathrm{e}$, muito menos, à sua própria dignidade (SIQUEIRA, 2016, p. 102).

Justifica-se a aplicação direta ou imediata dos direitos fundamentais no âmbito das relações trabalhistas pela essência intangível do núcleo dos direitos fundamentais do trabalho, em especial, estes denominados inespecíficos, frente a desigualdade entre os sujeitos da relação laboral manifestada, muitas vezes, pelo poder concentrado nas mãos dos empresários, de forma

$15 \quad$ Art. $7^{\mathrm{o}}$ da CRFB.

Rev. de Direitos Fundamentais nas Relações do Trabalho, Sociais e Empresariais | e-ISSN: 2525-9903 | Maranhão | v. 3 | n. 2 | 


\section{O IMPACTO DA TECNOLOGIA NAS RELAÇÕES DE TRABALHO: UMA ANÁLISE À LUZ DA TEORIA DA EFICÁCIA HORIZONTAL DOS DIREITOS FUNDAMENTAIS INESPECÍFICOS DOS TRABALHADORES}

a garantir a dignidade do trabalhador, além de se prevenir abusos de direito do empregador (SIQUEIRA, 2016).

Ainda, com relação à aplicação direta dos direitos fundamentais nas relações trabalhistas, Amaral (2014), afirma que seria a forma mais eficaz existente, em tese, para se proteger os direitos fundamentais do trabalhador quando sujeito ao poder privado de seu empregador.

Diante deste contexto das novas tecnologias nas relações de trabalho, grandes avanços nos meios de comunicação, monitoramento e controle da execução do labor, e a busca constante da maior lucratividade, constata-se que a teoria da eficácia horizontal dos direitos fundamentais pode dar a devida proteção aos direitos fundamentais da personalidade do trabalhador, cada vez mais vulnerável na sua condição de operário e ser humano, permitindo-lhe condições de estabelecer um meio de trabalho digno, sadio, além de maior proteção dos direitos no âmbito das relações trabalhistas.

\section{CONSIDERAÇÕES FINAIS}

Os direitos fundamentais têm o condão de promover a dignidade das pessoas, oferecendo-lhes condições mínimas de uma vida plena nas mais diversas esferas, inclusive, nas relações de trabalho.

Com o uso excessivo dos aparatos tecnológicos nas relações de trabalho surge o conflito entre a autonomia privada, representada pelo direito de propriedade do empregador, exercido mediante o seu poder diretivo, e os direitos fundamentais inespecíficos do trabalhador, tais como, o direito à privacidade, à intimidade, à imagem, entre outros e por consequência, fere-se a dignidade humana, núcleo dos direitos fundamentais.

Diante do conflito existente nessa relação laboral, estritamente privada, os direitos fundamentais devem ser aplicados de forma direta e ponderada, com fundamento na teoria da eficácia horizontal dos direitos fundamentais. Referida teoria vem ganhando espaço no ordenamento jurídico, mormente quando violados direitos inespecíficos dos trabalhadores.

Em dadas situações como a mencionada, que envolvam direitos da mesma magnitude, a fim de se resolver o conflito existente, utiliza-se a técnica da ponderação aplicada ao caso concreto. Para tanto, os critérios da defesa da dignidade da pessoa humana e da posição de 
desigualdade do sujeito vulnerável na relação laboral deve prevalecer frente ao direito de propriedade do empregador.

Portanto, tem-se que a eficácia horizontal dos direitos fundamentais trata-se de uma importante ferramenta para a efetiva tutela da dignidade da pessoa humana trabalhadora, pois nem mesmo a fundamentabilidade atribuída ao direito de propriedade, exercido muitas vezes pelo uso excessivo de aparatos tecnológicos utilizados pelo empregador na busca da proteção deste mesmo direito, pode, em casos tais, isentar àquele que detém o poder diretivo, de respeitar o mínimo necessário para a garantia dos direitos da personalidade do trabalhador.

\section{REFERÊNCIAS}

AMARAL, Júlio Ricardo de Paula. Eficácia dos direitos fundamentais nas relações trabalhistas. 2. Ed. São Paulo: LTr, 2014.

BARROS, Juliana Augusta Medeiros de. A utilização de Meios Eletrônicos no Ambiente de Trabalho: a colisão entre os direitos à intimidade e à privacidade do empregado e o poder diretivo do empregador. São Paulo: LTr, 2002.

BARRETTO, Vicente de Paulo. O fetiche dos direitos humanos e outros temas. Rio de janeiro: Lumen Juris, 2010.

BONAVIDES, Paulo. Curso de Direito Constitucional. São Paulo: Malheiros, 2000.

BRASIL. Lei no 10.406, de 10 de janeiro de 2002. Institui o Código Civil. Disponível em: <http://www.planalto.gov.br/ccivil_03/leis/2002/L10406.htm>. Acesso em 30 jul. 2017.

1988. Constituição: República Federativa do Brasil de 1988. Brasília, DF: Senado Federal,
em: <http://www.planalto.gov.br/ccivil_03/constituicao/constituicaocompilado.htm>. Acesso em 30 jul. 2017.

Decreto-lei $\mathbf{n}^{0}$ 5.452, de $1^{\circ}$ de maio de 1943. Aprova a Consolidação das Leis do Trabalho. Disponível em: < http://www.planalto.gov.br/ccivil_03/decreto-lei/Del5452.htm>. Acesso em: 30 jul. 2017.

Lei $\mathbf{n}^{\circ}$ 6.938, de 31 de agosto de 1981. Dispõe sobre a Política Nacional do Meio Ambiente, seus fins e mecanismos de formulação e aplicação, e dá outras providências. Disponível em: < http://www.planalto.gov.br/ccivil_03/leis/L6938.htm>. Acesso em: 30 jul. 2017.

CAMARGO, Daniel Marques. Jurisdição Crítica e Direitos Fundamentais. São Paulo: Núria Fabris: 2009.

Rev. de Direitos Fundamentais nas Relações do Trabalho, Sociais e Empresariais | e-ISSN: 2525-9903 | Maranhão | v. 3 | n. 2 | p. 66 - 87 | Jul/Dez. 2017. 
CAMINO, Carmem. Direito Individual do Trabalho. Porto Alegre: Síntese, 2004, p. 229.

DELGADO, Gabriela Neves. A constitucionalização dos direitos trabalhistas e os reflexos no mercado de trabalho. Revista LTr, São Paulo, ano 72-05, p. 564-565, maio de 2008.

FINCATO, Denise Pires (Org.). Novas tecnologias e relações de Trabalho: reflexões. Porto Alegre: Magister, 2011.

FINCATO; GUIMARÃES, MATTE (Orgs.). Direito e Tecnologia - Reflexões

Sociojurídicas. Porto Alegre: Livraria do Advogado, 2014.

GIDDENS, Antony. A terceira via: reflexões sobre o impasse político atual e o futuro da social-democrata. Tradução de Maria Luiza X. De A. Borges. Rio de Janeiro: Record, 2000.

GOLDSCHMIDT, Rodrigo. Flexibilização dos direitos trabalhistas: ações afirmativas da dignidade da pessoa humana como forma de resistência. São Paulo: LTr, 2009.

LASTRES, Helena Maria Martins; FERRAZ, João Carlos. Economia da Informação, do conhecimento e do aprendizado. In: Informação e globalização na era do conhecimento. Helena M. M. Lastres e Sarita Albagli (Orgs.). Rio de Janeiro: Campus, 1999.

MAGANO, Octávio Bueno. Do Poder Diretivo na Empresa. São Paulo: Saraiva, 1982.

MANTOVANI JUNIOR, Laert. O Direito Constitucional à Intimidade e à Vida Privada do Empregado e o Poder Diretivo do Empregador. São Paulo: Ltr, 2010,

MARQUES, Carlos Alexandre Michaello; STOLZ Sheila (Orgs.). Teletrabalho. São Paulo: LTr, 2017.

MELO, Adriana Zawada. A dignidade da pessoa humana como fundamentoda eficácia horizontal dos direitos fundamentais. In: GOZZO, Débora (Coord.). Informação e Direitos Fundamentais: a eficácia horizontal das normas constitucionais. São Paulo: Saraiva, 2012.

MELLO, Alex Fiúza. O primeiro manifesto da "globalização. In: Cultura Vozes. São Paulo: Vozes. n. 1, ano 92, v. 92, 1998.

MORAES, Alexandre de. Direito Constitucional. 14. ed. São Paulo: Atlas, 2003.

OLIVEIRA, Christiana Dárc Damasceno. O Direito do Trabalho Contemporâneo. Efetividade dos Direitos Fundamentais e dignidade da pessoa humana no mundo do trabalho. São Paulo: LTr, 2010.

Rev. de Direitos Fundamentais nas Relações do Trabalho, Sociais e Empresariais | e-ISSN: 2525-9903 | Maranhão | v. 3 | n. 2 | p. 66 - 87 | Jul/Dez. 2017. 
SARMENTO, Daniel. Direitos Fundamentais e Relações Privadas. 2. Ed. Rio de Janeiro: Lumen Juris, 2010.

SIQUERIA, Rodrigo Espiúca dos Anjos. Relações de trabalho e direitos fundamentais sociais. Curitiba: Juruá, 2016.

SOUTO MAIOR, Jorge Luiz. Do Direito à desconexão do trabalho. Revista do Departamento de Direito do Trabalho e da Seguridade Social, São Paulo, v, 1, n. 1, p. 92, jan/jun2006.

STEINMETZ, Wilson. A vinculação dos Particulares a Direitos Fundamentais. São Paulo: Malheiros, 2004.

TOFFER, Alvin. Powershift: as mudanças do poder - um perfil da sociedade do século XXI pela análise das transformações na natureza do poder. São Paulo: Record, 1995.

VECCHI, Ipojucan Demétrius. Direito material: noções introdutórias, relações de emprego e contrato de trabalho. Curitiba: Juruá, 2016.

, Contrato de trabalho \& a eficácia dos direitos humanos fundamentais de primeira dimensão: possibilidade de concretização. Curitiba: Juruá, 2009. Eficácia dos Direitos Fundamentais nas relações privadas: o caso da relação e emprego. Revista Tribunal Superior do Trabalho. Brasília, v. 77, n. 3, p. 111-135, jul./set. 2011. 